\title{
DÜBLIN
}

Technological University Dublin

ARROW@TU Dublin

\section{Improved Efficiency of Brewer's Spent Grain Arabinoxylans by Ultrasound-Assisted Extraction}

\author{
Sofia Reis \\ Technological University Dublin, sofiafreis@gmail.com \\ Elisabete Coelho \\ Universidade de Aveiro, ecoelho@ua.pt \\ Manuel Coimbra \\ Universidade de Aveiro, mac@ua.pt
}

See next page for additional authors

Follow this and additional works at: https://arrow.tudublin.ie/schfsehart

Part of the Food Chemistry Commons

\section{Recommended Citation}

Reis, S.F. et al. (2015) Improved efficiency of brewer's spent grain arabinoxylans by ultrasound-assisted extraction. Ultrasonics Sonochemistry, 24, pp.155-164. doi:10.1016/j.ultsonch.2014.10.010

This Article is brought to you for free and open access by the School of Food Science and Environmental Health at ARROW@TU Dublin. It has been accepted for inclusion in Articles by an authorized administrator of ARROW@TU Dublin. For more information, please contact arrow.admin@tudublin.ie, aisling.coyne@tudublin.ie, gerard.connolly@tudublin.ie.

Funder: Irish Department of Agriculture, Food and the Marine

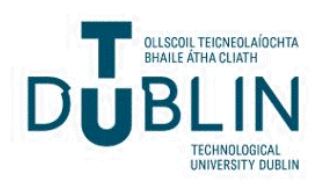




\section{Authors}

Sofia Reis, Elisabete Coelho, Manuel Coimbra, and Nissreen Abu-Ghannam

This article is available at ARROW@TU Dublin: https://arrow.tudublin.ie/schfsehart/153 


\title{
Improved efficiency of brewer's spent grain arabinoxylans by ultrasound-assisted extraction
}

\author{
Sofia F. Reis ${ }^{a}$, Elisabete Coelho ${ }^{\mathrm{b}}$, Manuel A. Coimbra ${ }^{\mathrm{b}}$, Nissreen Abu-Ghannam ${ }^{\mathrm{a}, *}$ \\ a School of Food Science and Environmental Health, College of Sciences and Health, Dublin Institute of Technology, Cathal Brugha St., Dublin 1, Ireland \\ ${ }^{\mathrm{b}}$ QOPNA, Departamento de Química, Universidade de Aveiro, 3810-193 Aveiro, Portugal
}

\section{A R T I C L E I N F O}

\section{Article history:}

Received 18 July 2014

Received in revised form 2 October 2014

Accepted 9 October 2014

Available online $\mathrm{xxxx}$

\section{Keywords:}

Ultrasound-assisted extraction

Arabinoxylans

Brewer's spent grain

RSM

\begin{abstract}
A B S T R A C T
Arabinoxylan (AX) rich extracts from brewer's spent grain (BSG) were produced by the application of ultrasound-assisted extraction (UAE) and conventional alkaline extraction (AKE). UAE and AKE were optimised for the production of the highest yield of ethanol insoluble material using response surface methodology (RSM). The efficiency of UAE was established by the significant reduction of time ( $7 \mathrm{~h}$ to $25 \mathrm{~min}$ ) and energy when compared to AKE, to recover similar amounts of AX (60\%) from BSG, leading to the production of starch-free AX-rich extracts.
\end{abstract}

(ㄷ) 2014 Elsevier B.V. All rights reserved.

\section{Introduction}

Arabinoxylans (AX) are the main non-starch polysaccharide of cereal grains such as wheat, barley, oat, corn and rice. The AX are composed of $\beta$-D- $(1 \rightarrow 4)$-linked-xylopyranosyl residues to which $\alpha$-L-arabinofuranose units are linked as side chains, with some of them substituted with monomeric or dimeric ferulic acid residues (Fig. 1) [1]. Similar to other non-digestible carbohydrates, AX are of particular interest in the formulation of functional foods due to the health benefits associated with their consumption [2]. They have been classified as prebiotics because they (i) are not hydrolysed nor absorbed in the upper part of the gastrointestinal tract, (ii) maintain a good gastrointestinal environment and (iii) selectively stimulate the microflora that confer benefits upon the host wellbeing and health [3].

Brewer's spent grain (BSG) is the residue left after barley malting and separation of the wort (fermentation medium to produce beer) during the brewing process. BSG is the most abundant brewing by-product amounting to around $85 \%$ of total by-products generated by the brewing industry. Million of tonnes of BSG are produced annually across Europe and common applications are direct disposal in a landfill or use as an animal feed. BSG is a lignocellulosic material composed of AX (28\%), cellulose (17\%) and lignin $(28 \%)[4,5]$. As the germinated grain during brewing has already been submitted to a hot water extraction process, the

\footnotetext{
* Corresponding author. Tel.: +353 (0) 14027570

E-mail addresses: sofiafreis@gmail.com (S.F. Reis), ecoelho@ua.pt (E. Coelho), mac@ua.pt (M.A. Coimbra), nissreen.abughannam@dit.ie (N. Abu-Ghannam).
}

BSG AX are mostly not extractable with water. Thus, chemical and/or enzymatic methods need to be used for their extraction. These include sequential extraction with mild and strong alkali solutions [6,7] and sequential extraction with alkali solution and a mixture of feruloyl esterases and glycoside hydrolases. This last extraction method allows for the recovery of phenolic acids and diferulate AX oligosaccharides [8]. Autohydrolysis of BSG, an environmentally friendly treatment carried out in a reactor with hot water or steam, promotes the recovery of several AX oligosaccharide (AXOS) mixtures [9]. More recently, a sequential extraction applying microwave superheated water and dilute alkali extraction of BSG AX was proposed, separating AX, AXOS, and feruloylated AXOS from the proteins and residual starch [10].

Ultrasound-assisted extraction (UAE) is a process that uses acoustic energy and solvents to extract target compounds from various plant matrices. The application of high-intensity ultrasound causes pressure fluctuations, which propagate through the material. These fluctuations give rise to microscopic bubbles that are highly unstable and collapse within a few milliseconds after their formation. In the wake of the collapse, high shear forces are applied to any material that is present in the vicinity of these cavitational bubbles. In addition to the mechanical shear forces, the temperature in the vicinity of the bubbles increases. The ultrasound pressure waves and resulting cavitation phenomena are able to break cell walls, promoting the release of the contents of the cell into the extraction medium $[11,12]$.

UAE has already been used to obtain xylans from corn cobs $[13,14]$, corn bran [15], wheat straw $[16,17]$, buckwheat hulls [18], sugarcane bagasse [19], wheat bran [20] and almond shells 


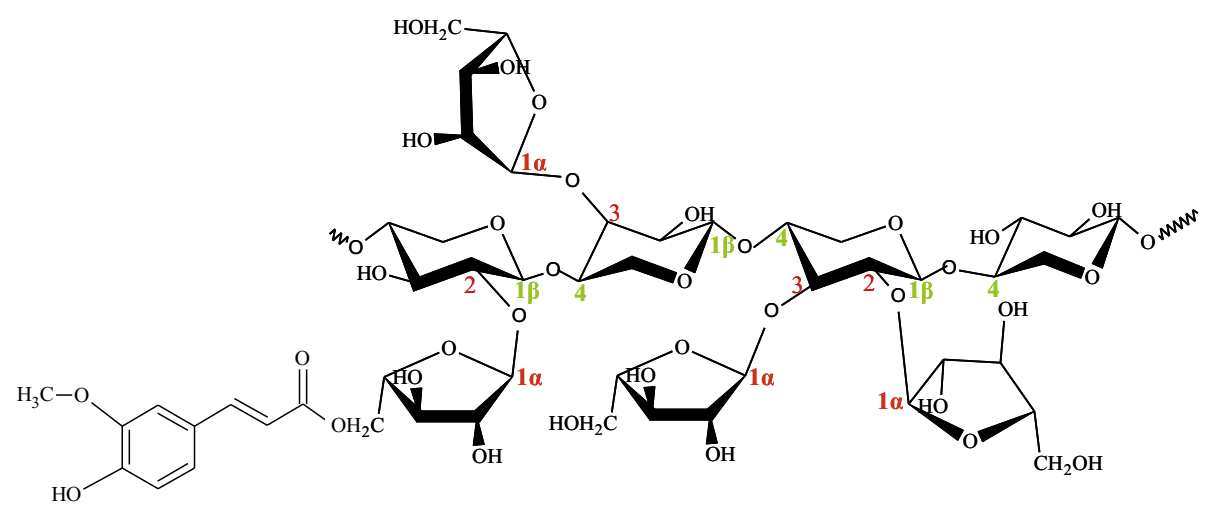

Fig. 1. Arabinoxylans structure.

[21]. The advantages reported are the substantial shortening of extraction time, solvent consumption, and extraction temperature, resulting in higher yields and purity of polysaccharides with no significant structural changes and no negative effects in their functional properties. However, high intensity ultrasound can break down polymers, which may negatively affect polysaccharides [22].

Due to the high demand of $A X$ owing to their potential health benefits as dietary fibre and as prebiotics, in addition to the abundant availability of BSG as a source of AX, this work aims at examining the efficiency of ultrasound-assisted extraction in the production of AX-rich extracts in comparison to typical alkaline extraction procedures.

\section{Material and methods}

\subsection{Chemicals}

All chemicals were purchased from Sigma-Aldrich (Wicklow, Ireland) except for sulphuric acid, acetone, dichloromethane and ethanol, which were purchased from Fisher scientific (Ballycoolin, Ireland).

\subsection{Brewer's spent grain (BSG)}

BSG was obtained from the micro distillery plant located at University College Cork, Cork (Ireland). The dried BSG was coarsely ground to $250 \mu \mathrm{m}$ particle size and stored in polyethylene bags at $-20^{\circ} \mathrm{C}$ until further use.

\subsection{Ultrasound-assisted extraction (UAE)}

\subsubsection{Ultrasound pre-washing treatment with water}

Suspensions of BSG ( $2 \mathrm{~g})$ and distilled water $(50 \mathrm{~mL})$ were processed at a constant frequency of $20 \mathrm{kHz}$ using a $750 \mathrm{~W}$ ultrasonic processor (VC 750, Sonics and Materials Inc., Newtown, USA) using a $13 \mathrm{~mm}$ diameter solid probe. Different amplitudes (8\%, 25\%, 50\%, $75 \%, 92 \%$ and $100 \%$ ) combined with different times (3.3, 5, 7.5, 10 and $11.7 \mathrm{~min}$ ) were applied with pulse durations of $5 \mathrm{~s}$ on and $5 \mathrm{~s}$ off. The ultrasound probe was submerged up to $25 \mathrm{~mm}$ in the sample. The residue was separated from the supernatant by centrifugation at $14,400 \mathrm{rpm}$ for $20 \mathrm{~min}$, and then resuspended in distilled water $(50 \mathrm{~mL})$ and autoclaved at $120^{\circ} \mathrm{C}$ for different times $(4.8,15,30,45$ and $55 \mathrm{~min})$.

\subsubsection{Ultrasound alkaline extraction}

The autoclaved residue was suspended in an alkali solution $(0.3$, $1,2,3$ and $3.7 \mathrm{M}$ ) and submitted to ultrasound treatment by combining different amplitudes (8\%, 25\%, 50\%, 75\%, 92\% and 100\%) and times (3.3, 5, 7.5, 10 and $11.7 \mathrm{~min}$ ) with pulse durations of $5 \mathrm{~s}$ on and $5 \mathrm{~s}$ off. The suspensions were then neutralised with $\mathrm{HCl}$ until pH 6-7 was reached and subsequently centrifuged. The supernatants were precipitated with 5 volumes of ethanol (96\%) and the alcohol insoluble material was recovered as a powder; after centrifugation at $14,400 \mathrm{rpm}$ for $10 \mathrm{~min}$, solubilisation in distilled water, dialysis using a cellulose acetate membrane of $12 \mathrm{kDa}$ cut off (Sigma, D9652) and freeze-drying. The scheme for the isolation of the polysaccharide fractions is shown in Fig. 2.

The ultrasonic intensity (UI) was determined using the following formula:

$\mathrm{UI}=4 P / \pi D^{2}$

where $P$ is the ultrasonic power (W) and $D$ is the probe diameter (cm). Ultrasonic power was calculated using the following formula:

$P=m C_{p}(d T / d t)_{t=0} \pi D^{2}$

where $m$ is the mass $(\mathrm{g}), C_{p}$ is the specific heat $\left(\mathrm{H}_{2} \mathrm{O}-4.187 \mathrm{~J} \mathrm{~g}^{-1}\right.$ 。 $\left.\mathrm{C}^{-1} ; 2 \mathrm{M} \mathrm{KOH}-0.93 \mathrm{~J} \mathrm{~g}^{-1}{ }^{\circ} \mathrm{C}^{-1}\right)$ and $(d T / d t)$ is the change in temperature over time $\left({ }^{\circ} \mathrm{C} \mathrm{s}^{-1}\right)$.

\subsection{Alkaline extraction (AKE)}

BSG samples were also extracted using different concentrations $(1,2,3,4$ and $5 \mathrm{M})$ of $\mathrm{KOH}$ solutions with $20 \mathrm{mM} \mathrm{NaBH}_{4}$, in an incubator (Innova 42, Mason technology, Dublin, Ireland) over different times (1, 4, 7, 10 and $13 \mathrm{~h})$ and temperatures $(25,35,45,55$ and $65^{\circ} \mathrm{C}$ ). After each alkaline extraction the same steps described after ultrasound treatment using alkali solution (Section 2.3.2) were followed.

\subsection{Sugar analysis}

Neutral sugars were released by Saeman hydrolysis and analysed as their alditol acetates by gas chromatography $[23,24]$ using a FISONS 8340 chromatograph with a split injector (split ratio 1:60) and a FID detector. A DB-225 column (Agilent J\&W, USA; $30 \mathrm{~m} \times 0.25 \mathrm{~mm} \times 0.15 \mu \mathrm{m})$ was used. The injector and detector temperatures were 220 and $230^{\circ} \mathrm{C}$, respectively. The oven temperature program started at $200-220^{\circ} \mathrm{C}$ at a rate of $40^{\circ} \mathrm{C}$ per min and was held at $220^{\circ} \mathrm{C}$ for $15 \mathrm{~min}$, then increased up to $230^{\circ} \mathrm{C}$ with a rate of $20^{\circ} \mathrm{C}$ per min and was held at $230^{\circ} \mathrm{C}$ for $1 \mathrm{~min}$. The flow rate of the carrier gas $\left(\mathrm{H}_{2}\right)$ was set at $1 \mathrm{~mL} / \mathrm{min}$ at $200^{\circ} \mathrm{C}$. Uronic acids (UA) were determined colorimetrically according to Coimbra et al. [23]. The hydrolysis of all samples was done in duplicate and each sample was injected twice. 


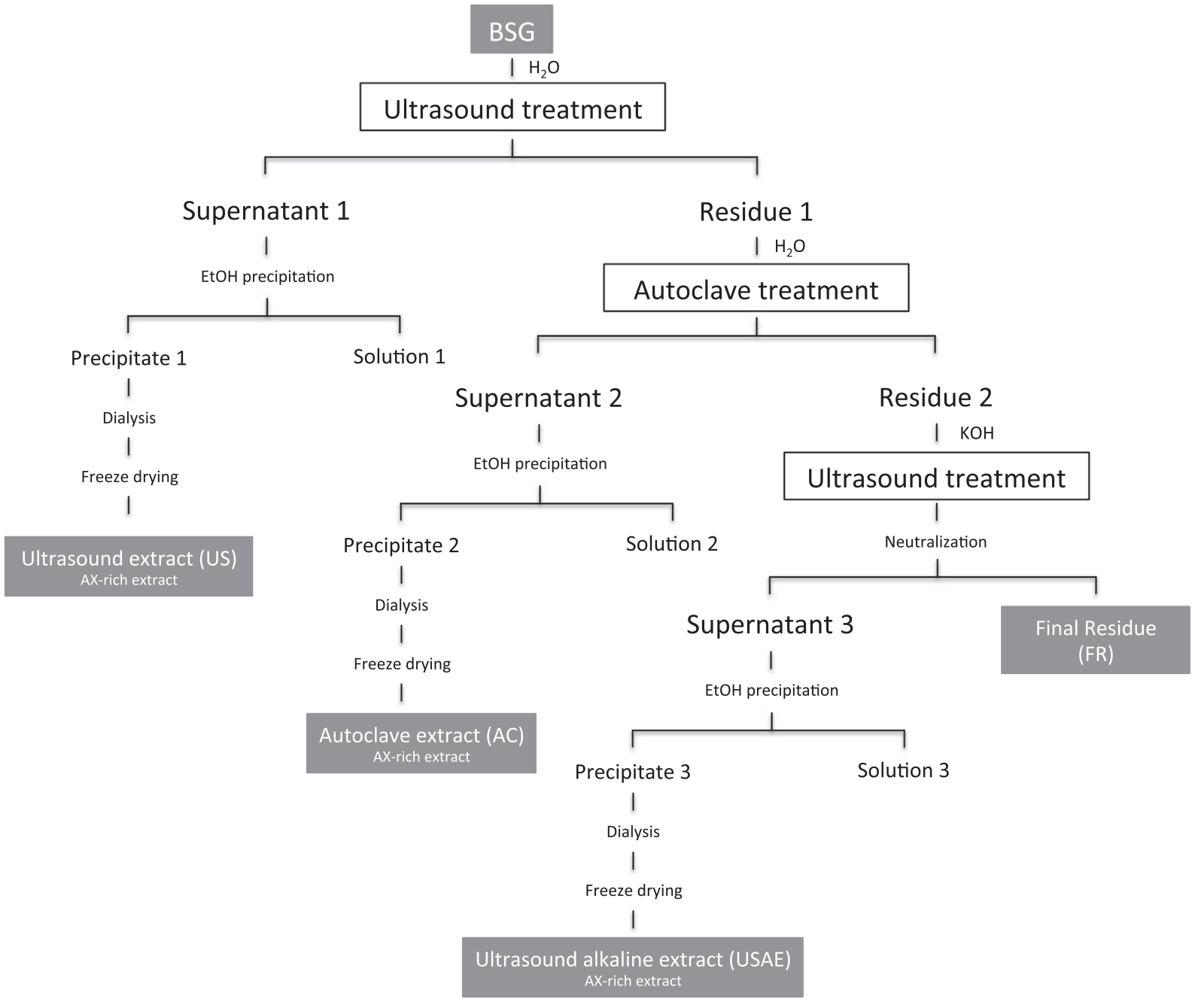

Fig. 2. Scheme for the isolation of alcohol insoluble material from BSG by ultrasound-assisted extraction (UAE).

Table 1

Experimental designs and corresponding response values for UAE of BSG AX.

\begin{tabular}{|c|c|c|c|c|c|c|c|c|c|c|c|c|c|c|}
\hline \multirow[b]{3}{*}{1} & \multicolumn{7}{|c|}{ Ultrasound + Autoclave extracts (USAC) } & \multicolumn{7}{|c|}{ Ultrasound Alkaline extract (USAE) } \\
\hline & \multicolumn{2}{|l|}{$X_{\mathrm{USAC} 1}$} & \multicolumn{2}{|c|}{$X_{\mathrm{USAC} 2}$} & \multicolumn{2}{|c|}{$X_{\mathrm{USAC} 3}$} & \multirow{2}{*}{$\begin{array}{l}Y \\
3.9\end{array}$} & \multicolumn{2}{|c|}{$X_{\mathrm{USAE} 1}$} & \multicolumn{2}{|c|}{$X_{\mathrm{USAE} 2}$} & \multicolumn{2}{|c|}{$X_{\mathrm{USAE} 3}$} & \multirow{2}{*}{$\begin{array}{l}Y \\
19.5\end{array}$} \\
\hline & 7.5 & $(0)$ & 92 & (2) & 30 & (0) & & 5.0 & $(-1)$ & 75 & (1) & 3.0 & (1) & \\
\hline 2 & 11.7 & (2) & 50 & (0) & 30 & (0) & 3.0 & 7.5 & $(0)$ & 92 & (2) & 2.0 & (0) & 20.7 \\
\hline 3 & 7.5 & $(0)$ & 50 & (0) & 5 & $(-2)$ & 1.8 & 7.5 & $(0)$ & 50 & $(0)$ & 2.0 & (0) & 19.8 \\
\hline 4 & 10.0 & (1) & 75 & (1) & 15 & $(-1)$ & 3.4 & 7.5 & $(0)$ & 8 & $(-2)$ & 2.0 & (0) & 10.7 \\
\hline 5 & 7.5 & $(0)$ & 8 & $(-2)$ & 30 & (0) & 1.9 & 10.0 & (1) & 75 & (1) & 3.0 & (1) & 18.1 \\
\hline 6 & 5.0 & $(-1)$ & 25 & $(-1)$ & 15 & $(-1)$ & 1.6 & 11.7 & (2) & 50 & $(0)$ & 2.0 & (0) & 19.4 \\
\hline 7 & 10.0 & (1) & 25 & $(-1)$ & 45 & (1) & 2.3 & 7.5 & $(0)$ & 50 & $(0)$ & 3.7 & (2) & 20.1 \\
\hline 8 & 10.0 & (1) & 75 & (1) & 45 & (1) & 3.4 & 10.0 & (1) & 25 & $(-1)$ & 3.0 & (1) & 16.4 \\
\hline 9 & 7.5 & $(0)$ & 50 & (0) & 30 & (0) & 2.0 & 10.0 & (1) & 75 & (1) & 1.0 & $(-1)$ & 17.6 \\
\hline 10 & 7.5 & $(0)$ & 50 & (0) & 55 & (2) & 2.5 & 5.0 & $(-1)$ & 25 & $(-1)$ & 3.0 & (1) & 16.1 \\
\hline 11 & 7.5 & $(0)$ & 50 & (0) & 30 & (0) & 2.0 & 5.0 & $(-1)$ & 25 & $(-1)$ & 1.0 & $(-1)$ & 6.6 \\
\hline 12 & 3.3 & $(-2)$ & 50 & (0) & 30 & (0) & 1.8 & 5.0 & $(-1)$ & 75 & (1) & 1.0 & $(-1)$ & 16.5 \\
\hline 13 & 5.0 & $(-1)$ & 75 & (1) & 45 & (1) & 2.7 & 3.3 & $(-2)$ & 50 & $(0)$ & 2.0 & (0) & 15.9 \\
\hline 14 & 10.0 & (1) & 25 & $(-1)$ & 15 & $(-1)$ & 2.1 & 7.5 & $(0)$ & 50 & $(0)$ & 0.3 & $(-2)$ & 6.0 \\
\hline 15 & 5.0 & $(-1)$ & 75 & (1) & 15 & $(-1)$ & 2.2 & 10.0 & (1) & 25 & $(-1)$ & 1.0 & $(-1)$ & 9.7 \\
\hline 16 & 5.0 & $(-1)$ & 25 & $(-1)$ & 45 & (1) & 2.5 & 7.5 & $(0)$ & 50 & (0) & 2.0 & $(0)$ & 17.0 \\
\hline
\end{tabular}

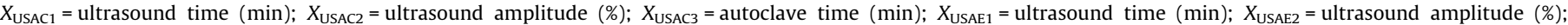
$\mathrm{X}_{\mathrm{USAE3}}=\mathrm{KOH}$ concentration $(\mathrm{M}) ; Y=$ Yield $(\%)$.

\subsection{Methylation analysis}

Glycosidic-linkage composition was determined by gas chromatography-quadrupole mass spectrometry (GC-qMS) of the partially methylated alditol acetates [25-27]. Briefly, the polysaccharides were methylated with $80 \mu \mathrm{L}$ of methyl iodide and the mixture was allowed to react for 20 min under stirring. The permethylated polysaccharides were hydrolysed with $0.5 \mathrm{~mL}$ of $2 \mathrm{M}$ 
Table 2

Regression coefficients and analysis of variance of uncoded units for UAE yield.

\begin{tabular}{llllll}
\hline \multirow{2}{*}{ Coefficient } & \multicolumn{3}{l}{ USAC } & & USAE \\
\cline { 2 - 3 } \cline { 5 - 6 } & Estimate & $p$-Value & & Estimate & $p$-Value \\
\hline$\beta 0$ & 0.3617 & & & -23.490 & \\
$\beta 1$ & 0.1038 & 0.0004 & 1.926 & 0.1806 \\
$\beta 2$ & -0.0257 & 0.0000 & & 0.460 & 0.0005 \\
$\beta 3$ & 0.0794 & 0.0038 & & 16.120 & 0.0003 \\
$\beta 11$ & -0.0013 & 0.8812 & & -0.051 & 0.5688 \\
$\beta 12$ & 0.0032 & 0.0139 & & -0.007 & 0.4462 \\
$\beta 13$ & -0.0040 & 0.0420 & & -0.265 & 0.2873 \\
$\beta 22$ & 0.0003 & 0.0209 & & -0.002 & 0.1047 \\
$\beta 23$ & -0.0002 & 0.2453 & & -0.063 & 0.0313 \\
$\beta 33$ & -0.0004 & 0.1238 & & -1.944 & 0.0102 \\
$R^{2}$ & 97.4 & & 95.4 & \\
\hline
\end{tabular}

USAC - ultrasound + autoclave extract; USAE - ultrasound alkaline extract.

trifluoroacetic acid $\left(1 \mathrm{~h}\right.$ at $121^{\circ} \mathrm{C}$ ) and dried by centrifugal evaporation. The reduction of monosaccharides was performed for $1 \mathrm{~h}$ at $30{ }^{\circ} \mathrm{C}$ with $20 \mathrm{mg}$ of sodium borodeuteride in $300 \mu \mathrm{L}$ of $2 \mathrm{M} \mathrm{NH}_{3}$. The acetylation was performed with $3 \mathrm{~mL}$ of acetic anhydride using $450 \mu \mathrm{L} \mathrm{1-methylimidazole} \mathrm{as} \mathrm{catalyst,} \mathrm{for} 30 \mathrm{~min}$ at $30^{\circ} \mathrm{C}$. The partially methylated alditol acetates were dissolved in $50-100 \mu \mathrm{L}$ of acetone and $0.2 \mu \mathrm{L}$ were injected and analysed by GC-qMS on an Agilent Technologies 6890N Network gas chromatograph, equipped with a $30 \mathrm{~m} \times 0.25 \mathrm{~mm}$ (i.d.), $0.1 \mu \mathrm{m}$ film thickness DB1 fused silica capillary column (J\&W Scientific Inc., CA, USA) connected to an Agilent 5973 quadrupole mass selective detector. The oven temperature was programmed as follows: $50-140{ }^{\circ} \mathrm{C}$ at $8{ }^{\circ} \mathrm{C} / \mathrm{min}$ (hold $5 \mathrm{~min}$ at $140^{\circ} \mathrm{C}$ ), to $150^{\circ} \mathrm{C}$ at $0.5^{\circ} \mathrm{C} / \mathrm{min}$ and then to $280^{\circ} \mathrm{C}$ at $40^{\circ} \mathrm{C} / \mathrm{min}$ (hold $1 \mathrm{~min}$ at $280^{\circ} \mathrm{C}$ ). The helium carrier gas had a flow rate of $1.7 \mathrm{~mL} / \mathrm{min}$ and the column head pressure was $2.8 \mathrm{psi}$. The mass spectrometer was operated in the electron impact mode (EI) at $70 \mathrm{eV}$ scanning in the range of $40-500 \mathrm{~m} / \mathrm{z}$, in a full scan acquisition mode. Identification was achieved by comparing with the standard mass spectra and with other spectra available at the laboratory made database.

\subsection{Determination of arabinoxylans $(A X)$}

The arabinoxylans content in the final extracts were calculated from the sum of total arabinose and total xylose quantified by methylation analysis, after correction for the presence of arabinogalactans (AG), assuming an arabinose to galactose ratio of 0.7 [28].

\subsection{Determination of protein}

The protein in the extracts was determined by using the BioRad protein assay kit (Bio-Rad, USA) based on the method of Bradford.

(a)
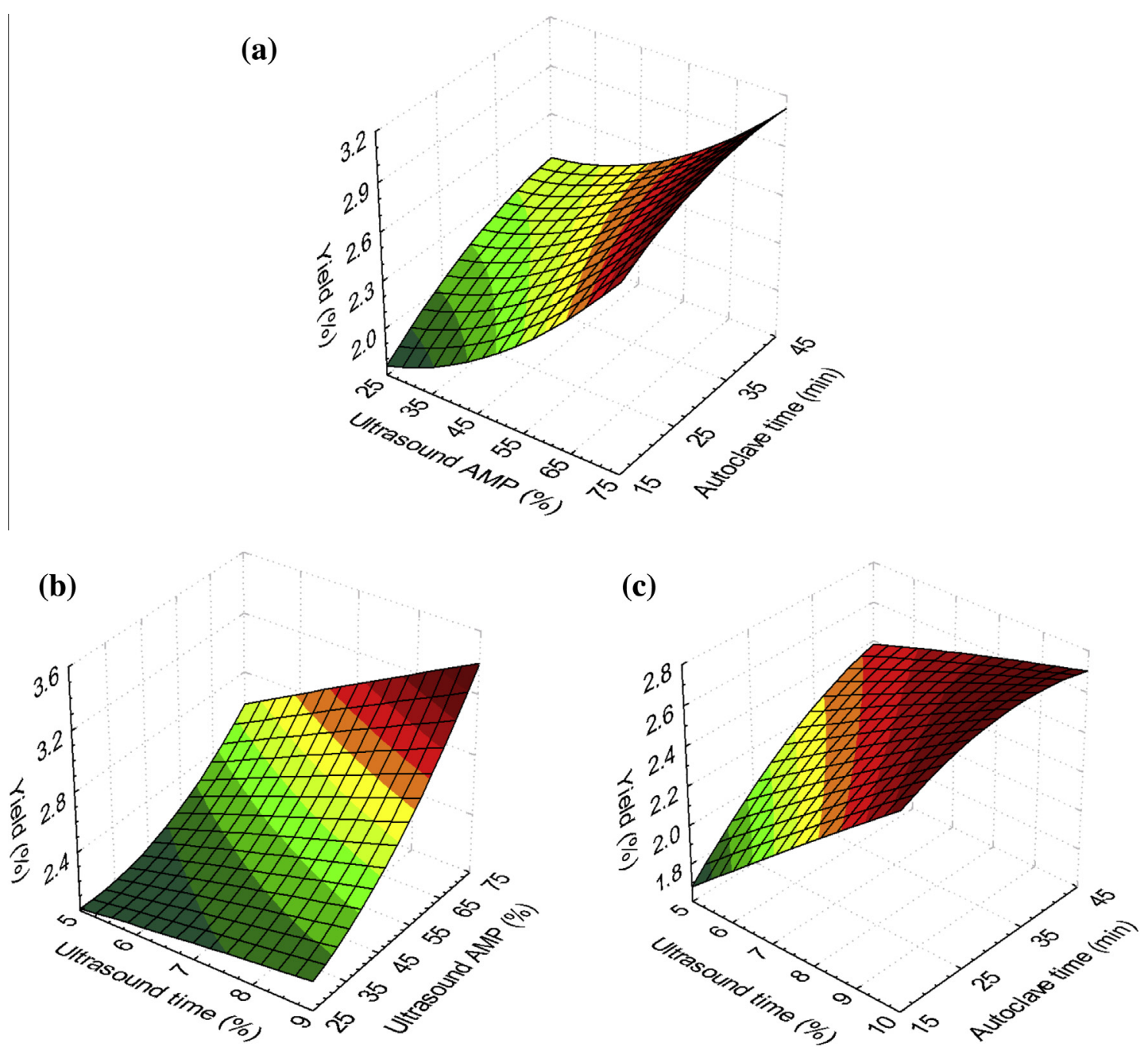

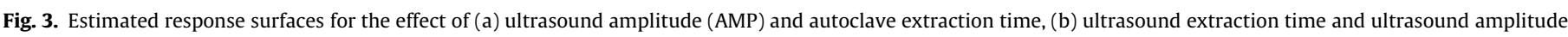
and (c) ultrasound extraction time and autoclave extraction time on the yield of ethanol insoluble material (USAC) obtained. 
Table 3

Sugar analysis after acid hydrolysis of BSG and the extracts obtained from UAE and AKE and the respective final residues.

\begin{tabular}{|c|c|c|c|c|c|c|c|c|}
\hline & \multirow[t]{2}{*}{ Yield (\%) } & \multicolumn{6}{|c|}{ Mol (\%) } & \multirow[t]{2}{*}{ Total sugar $(\mathrm{mg} / \mathrm{g})$} \\
\hline & & Ara & Xyl & Man & Gal & Glc & UA & \\
\hline BSG & - & 15 & 34 & 1 & 2 & 38 & 7 & 442 \\
\hline \multicolumn{9}{|l|}{ UAE } \\
\hline US & 2.2 & 26 & 29 & - & 3 & 27 & 15 & 437 \\
\hline$A C$ & 1.1 & 14 & 16 & - & 3 & 44 & 23 & 398 \\
\hline USAE & 20.3 & 25 & 65 & - & 2 & - & 8 & 474 \\
\hline $\mathrm{FR}_{\mathrm{UAE}}$ & - & 6 & 19 & - & - & 41 & 24 & 449 \\
\hline \multicolumn{9}{|l|}{ AKE } \\
\hline $\mathrm{AE}$ & 20.3 & 26 & 49 & - & 2 & 9 & 13 & 763 \\
\hline $\mathrm{FR}_{\mathrm{AKE}}$ & - & 9 & 25 & - & - & 66 & 0 & 475 \\
\hline
\end{tabular}

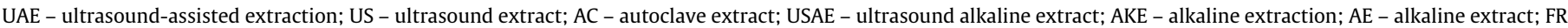
- final residue.

Table 4

Methylation analysis of the extracts obtained by UAE and AKE.

\begin{tabular}{|c|c|c|c|c|}
\hline \multirow[t]{2}{*}{ Linkage } & \multicolumn{3}{|c|}{ Ultrasound assisted extraction } & \multirow{2}{*}{$\begin{array}{l}\text { Alkaline extraction } \\
\mathrm{AE}\end{array}$} \\
\hline & US & $A C$ & USAE & \\
\hline t-Araf & 32.2 & 22.6 & 24.8 & 26.4 \\
\hline 2-Araf & 0.5 & 0.3 & 1.8 & 1.4 \\
\hline 3-Araf & 0.8 & 0.8 & 3.5 & 2.8 \\
\hline 5-Araf & 1.0 & 0.8 & 1.1 & 1.4 \\
\hline 3,5-Araf & - & - & 0.1 & - \\
\hline t-Xylp & 1.6 & 1.4 & 5.4 & 4.6 \\
\hline 3-Xylp & $\mathrm{t}$ & - & 0.2 & - \\
\hline 4-Xylp & 19.9 & 18.2 & 30.3 & 31.9 \\
\hline 2,4-Xylp & 3.2 & 3.6 & 12.8 & 8.3 \\
\hline 3,4-Xylp & 4.5 & 2.8 & 5.7 & 4.0 \\
\hline $2,3,4-\mathrm{Xyl} p$ & 9.8 & 4.6 & 10.7 & 6.7 \\
\hline t-Manp & $\mathrm{t}$ & 0.1 & - & $\mathrm{t}$ \\
\hline 2-Manp & 0.4 & 0.2 & - & 0.2 \\
\hline 6-Manp & - & - & - & $\mathrm{t}$ \\
\hline 2,6-Manp & - & - & - & $\mathrm{t}$ \\
\hline t-Galp & 0.4 & 0.3 & 1.4 & 0.9 \\
\hline 3-Galp & 0.7 & 0.5 & 0.2 & $\mathrm{t}$ \\
\hline 4-Galp & 0.2 & 0.1 & 0.2 & 0.2 \\
\hline 6-Galp & 0.5 & - & 0.2 & $\mathrm{t}$ \\
\hline 3,6-Galp & 0.3 & - & 0.2 & $\mathrm{t}$ \\
\hline t-Glcp & 2.3 & 1.8 & 0.2 & 0.9 \\
\hline 3-Glcp & 1.3 & 0.4 & - & 0.7 \\
\hline 4-Glcp & 18.6 & 41.0 & 0.8 & 8.5 \\
\hline 6-Glcp & 0.3 & 0.2 & $\mathrm{t}$ & 0.1 \\
\hline 4,6-Glcp & 1.1 & 0.3 & - & 0.3 \\
\hline Glucitol & 0.3 & - & 0.4 & 0.1 \\
\hline
\end{tabular}

US - ultrasound extract; AC - autoclave extract; USAE - ultrasound alkaline extract; $\mathrm{AE}$ - alkaline extract; $\mathrm{t}$-traces $(\mathrm{Mol} \%<0.1)$.

\subsection{Response surface methodology (RSM)}

A central composite rotatable design was used for the prewashing treatment of UAE to investigate the effects of three independent variables: ultrasound extraction time $\left(X_{1}\right)$, ultrasound amplitude $\left(X_{2}\right)$ and autoclave extraction time $\left(X_{3}\right)$ on the yield of ethanol insoluble material obtained. For the alkaline extraction in UAE the same design was used to investigate the effects of three independent variables: ultrasound extraction time $\left(X_{1}\right)$, ultrasound amplitude $\left(X_{2}\right)$ and alkali solution concentration $\left(X_{3}\right)$, on the yield of ethanol insoluble material obtained. In AKE another central composite rotatable design was used to investigate the effects of four independent variables: sample/solvent $(\mathrm{w} / \mathrm{v})$ ratio $\left(X_{1}\right)$, alkali solution concentration $\left(X_{2}\right)$, temperature $\left(X_{3}\right)$ and extraction time $\left(X_{4}\right)$, on the yield of ethanol insoluble material obtained. Results from preliminary trials were used to select suitable values for the independent variables. A second order polynomial Eq. (3) for the dependent variables was established to fit the experimental data. An analysis of variance (ANOVA) was carried out using STATGRAPHICS (Centurion XV.II 2.006) to determine the significance of the variables:

$$
\begin{aligned}
Y= & \beta 0+\beta 1 X_{1}+\beta 2 X_{2}+\beta 3 X_{3} \cdots+\beta 11 X_{1}^{2}+\beta 22 X_{2}^{2} \\
& +\beta 33 X_{3}^{2} \cdots+\beta 12 X_{1} X_{2}+\beta 13 X_{1} X_{3} \cdots
\end{aligned}
$$

where $X_{1}, X_{2}, X_{3} \ldots X_{1}^{2}, X_{2}^{2} \ldots X_{1} X_{2} \ldots$ are the independent variables with their linear, quadratic and interactive models, and $\beta 0, \beta 1$, $\beta 2 \ldots \ldots \ldots \beta 12$ are the regression coefficients of responses.

Response surface plots were designed using STATISTICA software (version 5.1, StatSoft Inc., Tulsa, USA).

\section{Results and discussion}

\subsection{Optimisation of UAE of arabinoxylan-rich extracts from BSG by RSM}

The procedure for UAE consisted of an ultrasound pre-washing treatment with water followed by an alkali extraction of the residue left (Fig. 2). Preliminary trials (data not shown) were conducted to estimate the optimum ratio of mass of sample to volume of solvent $(\mathrm{w}(\mathrm{g}) / \mathrm{v}(\mathrm{mL}))$ to be used in the experiments. The optimum $\mathrm{w} / \mathrm{v}$ ratio was achieved at 0.04 , allowing a good performance of the equipment for 5 min by using the highest ultrasound amplitude (100\%). After the ultrasound treatment with water, an autoclave procedure was applied as a complementary washing treatment for the residue. Following the pre-washing treatment using ultrasound and autoclave, an extraction of the residue left was performed with ultrasound using an alkali solution. This procedure was optimised by RSM for the yield of ethanol insoluble material and the experimental designs and respective response values are presented in Table 1.

\subsubsection{Ultrasound pre-washing treatment with water}

The ultrasound pre-washing treatment experimental design (USAC) optimised the ultrasound treatment time $\left(X_{1}\right)$, ultrasound amplitude $\left(X_{2}\right)$ and autoclave time $\left(X_{3}\right)$, in the ranges of 5$10 \mathrm{~min}, 25-75 \%$ and $15-45 \mathrm{~min}$, respectively (Table 1 ). A regression analysis was carried out to fit mathematical models to the experimental data and the regression coefficients for the uncoded variables are shown in Table 2. The model fitted to the USAC experimental design explains $97.4 \%$ of the yield variability and the $p$-values of regression and ANOVA analysis showed that six elements were significantly affecting the yield at $95 \%$ confidence level. The linear factor ultrasound amplitude $(\beta 2)$ was the main variable affecting the yield $(p \leqslant 0.05)$, followed by ultrasound time $(\beta 1)$ and autoclave time ( $\beta 3)$. The interaction between ultrasound time 
and amplitude ( $\beta 12$ ) was the fourth element affecting the yield, followed by the quadratic factor of amplitude $(\beta 22)$ and the interaction between ultrasound time and autoclave time ( $\beta 13)$.

The estimate response surfaces based on the experimental data (Fig. 3) shows that increasing ultrasound time $\left(X_{1}\right)$, ultrasound amplitude $\left(X_{2}\right)$ and autoclave time $\left(X_{3}\right)$ increases the yield. Autoclave time increased yield at low ultrasound amplitudes but had no effect on the yield when high ultrasound amplitudes were applied (Fig. 3a). Increasing ultrasound time increased the yield and the increment was higher when high ultrasound amplitudes were used (Fig. 3b). Also, the increase in ultrasound time decreased the influence of autoclaving time, indicating that when higher ultrasound times were applied, lower autoclaving times were needed (Fig. 3c).

The combination of an ultrasound treatment for 12 min at $92 \%$ amplitude and $23 \mathrm{~min}$ of autoclave treatment, predicted by the regression Eq. (3) fitted to the data, resulted in an optimum yield value of $4.8 \%$. In order to make use of all potentialities of the equipment, the amplitude was set at the maximum (100\%). The combining factors to achieve the maximum yield, using the regression equation, were 5 and $15 \mathrm{~min}$ of ultrasound and autoclave treatment, respectively. At this amplitude setting the extraction time decreased and the maximum predicted yield was $3.1 \%$. The exper- imental value obtained was $3.1 \pm 0.3 \%(n=16)$. The ultrasound intensity average as calculated by Eqs. (1) and (2) at this optimised point, was $14 \mathrm{~W} \mathrm{~cm}^{-2}$.

Sugar analysis (Table 3 ) of these optimised extracts revealed that the US extract ( $2 \%$ of the BSG biomass) was composed of $44 \%$ polysaccharides, and the AC extract (1\% of the BSG biomass) was composed of $40 \%$ polysaccharides. The major sugars identified were xylose, glucose, arabinose and uronic acids. Methylation analysis (Table 4) revealed the presence of high molar percentage of 4Glcp, especially in AC extracts, that could be diagnostic of starch. In addition to the presence of $A X$, inferred by the high molar percentage of 4-Xylp corresponding to the xylan backbone of $A X$, and tAraf accounting to the arabinofuranose AX side chain residues. These results suggest that the pre-washing treatment allows the removal of the BSG residual starch both by ultrasound and autoclave treatments. A first treatment with water and ultrasound was also reported as a refining step for the removal of contaminated starch and proteins [15] and to lower the amount of associated lignin to the xylans [19] before the alkaline extraction of xylans.

Despite AX already having been extracted from the germinated grain by the hot water extraction during the production of the wort, a portion of AX and starch is still trapped within the BSG

(a)

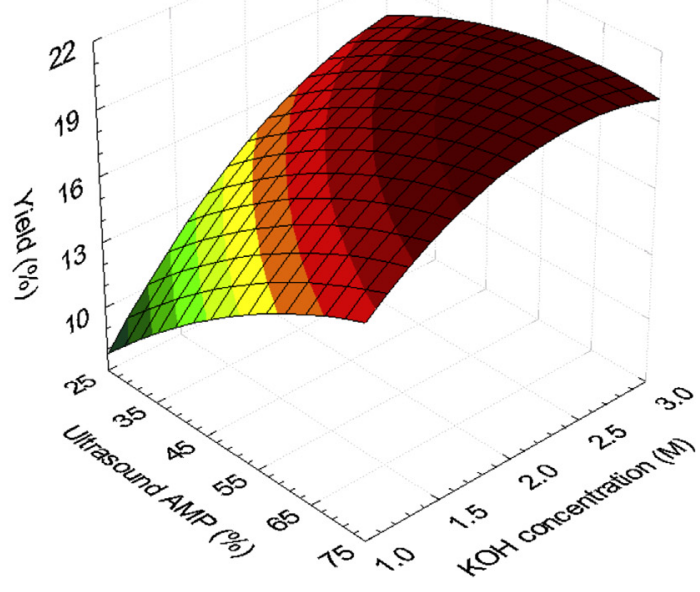

(b)

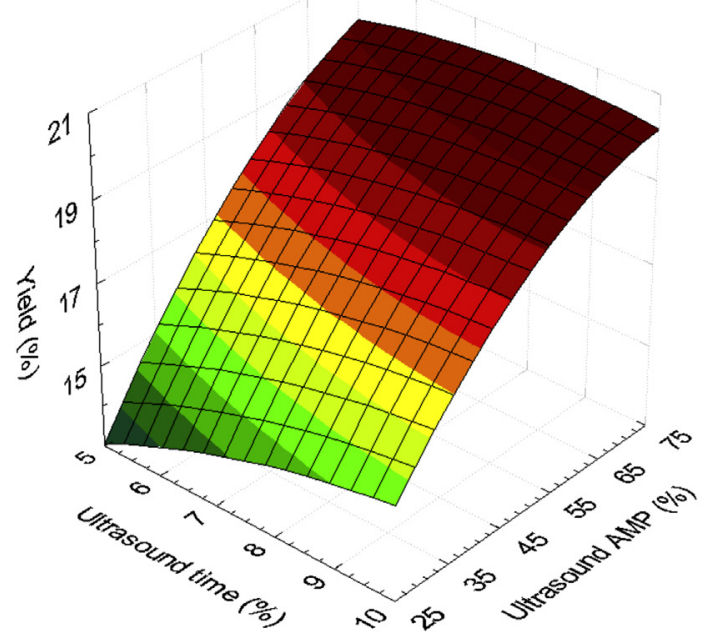

(c)

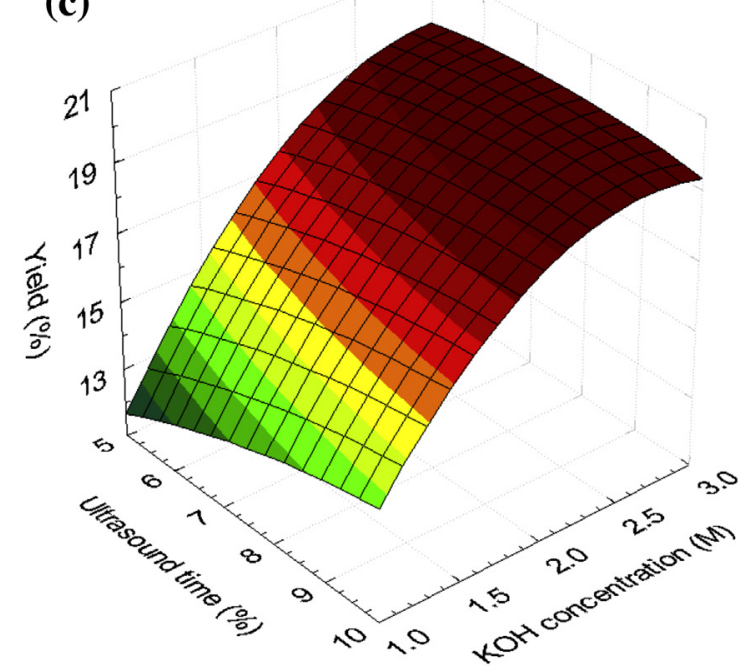

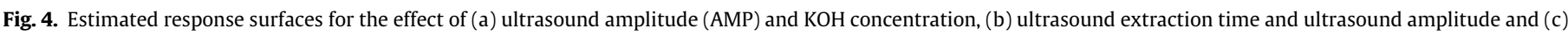
ultrasound extraction time and $\mathrm{KOH}$ concentration on the yield of ethanol insoluble material (USAE) obtained. 
Table 5

Experimental design and corresponding response values for AKE of BSG AX.

\begin{tabular}{|c|c|c|c|c|c|c|c|c|c|}
\hline & $X_{1}$ & & $X_{2}$ & & $X_{3}$ & & $X_{4}$ & & $Y$ \\
\hline 1 & 0.12 & (0) & 3 & $(0)$ & 65 & (2) & 7 & (0) & 4.1 \\
\hline 2 & 0.16 & (1) & 2 & $(-1)$ & 55 & (1) & 10 & (1) & 4.6 \\
\hline 3 & 0.16 & (1) & 2 & $(-1)$ & 55 & (1) & 4 & $(-1)$ & 5.8 \\
\hline 4 & 0.12 & (0) & 3 & $(0)$ & 45 & (0) & 7 & (0) & 18.3 \\
\hline 5 & 0.16 & (1) & 4 & (1) & 35 & $(-1)$ & 10 & (1) & 5.8 \\
\hline 6 & 0.16 & (1) & 4 & (1) & 35 & $(-1)$ & 4 & $(-1)$ & 7.3 \\
\hline 7 & 0.08 & $(-1)$ & 4 & (1) & 35 & $(-1)$ & 10 & (1) & 15.5 \\
\hline 8 & 0.04 & $(-2)$ & 3 & (0) & 45 & (0) & 7 & (0) & 20.8 \\
\hline 9 & 0.12 & (0) & 3 & $(0)$ & 45 & (0) & 7 & (0) & 21.5 \\
\hline 10 & 0.16 & (1) & 2 & $(-1)$ & 35 & $(-1)$ & 10 & (1) & 9.2 \\
\hline 11 & 0.08 & $(-1)$ & 2 & $(-1)$ & 35 & $(-1)$ & 10 & (1) & 11.0 \\
\hline 12 & 0.12 & (0) & 3 & (0) & 45 & (0) & 7 & (0) & 21.5 \\
\hline 13 & 0.12 & (0) & 3 & (0) & 45 & (0) & 7 & (0) & 21.6 \\
\hline 14 & 0.08 & $(-1)$ & 4 & (1) & 55 & (1) & 10 & (1) & 17.3 \\
\hline 15 & 0.08 & $(-1)$ & 2 & $(-1)$ & 55 & (1) & 4 & $(-1)$ & 14.3 \\
\hline 16 & 0.08 & $(-1)$ & 4 & (1) & 55 & (1) & 4 & $(-1)$ & 19.2 \\
\hline 17 & 0.12 & (0) & 3 & (0) & 25 & $(-2)$ & 7 & (0) & 10.3 \\
\hline 18 & 0.16 & (1) & 4 & (1) & 55 & (1) & 10 & (1) & 12.9 \\
\hline 19 & 0.12 & (0) & 5 & (2) & 45 & (0) & 7 & (0) & 25.0 \\
\hline 20 & 0.12 & (0) & 3 & (0) & 45 & (0) & 7 & (0) & 22.1 \\
\hline 21 & 0.08 & $(-1)$ & 2 & $(-1)$ & 35 & $(-1)$ & 4 & $(-1)$ & 15.8 \\
\hline 22 & 0.16 & (1) & 4 & (1) & 55 & (1) & 4 & $(-1)$ & 11.9 \\
\hline 23 & 0.12 & (0) & 3 & (0) & 45 & (0) & 1 & $(-2)$ & 20.7 \\
\hline 24 & 0.20 & (2) & 3 & $(0)$ & 45 & (0) & 7 & (0) & 15.0 \\
\hline 25 & 0.16 & (1) & 2 & $(-1)$ & 35 & $(-1)$ & 4 & $(-1)$ & 7.0 \\
\hline 26 & 0.08 & $(-1)$ & 4 & (1) & 35 & $(-1)$ & 4 & $(-1)$ & 9.9 \\
\hline 27 & 0.08 & $(-1)$ & 2 & $(-1)$ & 55 & (1) & 10 & (1) & 12.9 \\
\hline 28 & 0.12 & (0) & 3 & $(0)$ & 45 & (0) & 13 & (2) & 21.6 \\
\hline 29 & 0.12 & (0) & 1 & $(-2)$ & 45 & (0) & 7 & (0) & 9.5 \\
\hline
\end{tabular}

$X_{1}=$ sample/solvent ratio $(\mathrm{w} / \mathrm{v}) ; X_{2}=\mathrm{KOH}$ concentration $(\mathrm{M}) ; X_{3}=$ temperature $\left({ }^{\circ} \mathrm{C}\right)$ $X_{4}=$ time $(\mathrm{h}) ; Y=$ yield $(\%)$

Table 6

Regression coefficients and analysis of variance of uncoded units for AKE yield.

\begin{tabular}{lll}
\hline Coefficient & Estimate & $p$-Value \\
\hline$\beta 0$ & -79.90 & \\
$\beta 1$ & 200.00 & 0.0181 \\
$\beta 2$ & 3.37 & 0.0485 \\
$\beta 3$ & 3.59 & 0.8264 \\
$\beta 4$ & 1.13 & 0.9939 \\
$\beta 11$ & -1054.00 & 0.1566 \\
$\beta 12$ & 5.54 & 0.8519 \\
$\beta 13$ & -0.88 & 0.7674 \\
$\beta 14$ & 1.46 & 0.8823 \\
$\beta 22$ & -1.85 & 0.1237 \\
$\beta 23$ & 0.18 & 0.1559 \\
$\beta 24$ & 0.17 & 0.6607 \\
$\beta 33$ & -0.04 & 0.0024 \\
$\beta 34$ & -0.01 & 0.7884 \\
$\beta 44$ & -0.10 & 0.4491 \\
$R^{2}$ & 74.5 & \\
\hline
\end{tabular}

matrix by a proteinaceous barrier [29]. The ultrasound treatment seems to break the proteinaceous barrier in only $5 \mathrm{~min}$ at room temperature in contrast to a $24 \mathrm{~h}$ treatment using proteases at $40{ }^{\circ} \mathrm{C}$ to recover these water soluble AX [29].

\subsubsection{Ultrasound alkaline extraction}

The ultrasound alkaline extraction experimental design (USAE) started with the use of the optimum conditions achieved for the previous experimental design; $100 \%$ ultrasound amplitude for 5 min which was followed by $15 \mathrm{~min}$ autoclave treatment. The experimental design optimised the ultrasound extraction time $\left(X_{1}\right)$, ultrasound amplitude $\left(X_{2}\right)$ and alkali solution concentration $\left(X_{3}\right)$ in the ranges of $5-10 \mathrm{~min}, 25-75 \%$ and $1-3 \mathrm{M} \mathrm{KOH}$, respectively (Table 1 ).
The model fitted to the USAE experimental design explains $95.4 \%$ of the variability in the yield and the $p$-values of regression and ANOVA analysis showed that four effects have significant influence on the yield (Table 2), at 95\% confidence level. The main effect is the alkali solution concentration ( $\beta 3$ ), followed by ultrasound amplitude ( $\beta 2$ ), the quadratic factor of alkali solution concentration $(\beta 33)$ and the interaction of the ultrasound amplitude and alkali solution concentration ( $\beta 23)$. Estimate response surfaces based on the experimental data (Fig. 4) shows that the yield increases with the increase of ultrasound amplitude, alkali solution concentration and ultrasound extraction time. Alkali solution concentration and extraction time have been reported as important parameters that strongly affect the UAE yield of xylans [14,1618]. However, while at low ultrasound amplitudes the increase in alkali concentration increases strongly the yield, at high ultrasound amplitudes the increase in alkali concentration does not affect significantly the yield obtained (Fig. 4a). Although at a low level of significance, it was observed that prolonged ultrasound extraction time increases the yield with the increase of ultrasound amplitude (Fig. 4b). Also the increase in ultrasound extraction time at low alkali solution concentration increases significantly the yield, yet at high alkali solution concentration it showed no influence on the yield (Fig. 4c). These results suggest that higher ultrasound amplitudes promote the degradation of polymeric material, which is probably soluble in ethanol solutions or could be lost during the dialysis step and consequently leads to a decrease in the yield obtained. The results also suggest that the extent of degradation is a compromise between the alkali solution concentration and the ultrasound amplitude applied.

The optimum conditions chosen, using the regression equation fitted to the data, for maximising the yield of ethanol insoluble material were: ultrasound extraction time of $5 \mathrm{~min}$ at $100 \%$ ultrasound amplitude and $2 \mathrm{M} \mathrm{KOH}$. The predicted yield by the regression Eq. (3) was $20.2 \%$, and the experimental value observed was $20.3 \pm 0.4 \%(n=5)$. The ultrasound intensity average calculated by Eqs. (1) and (2) at this optimum point was $3 \mathrm{~W} \mathrm{~cm}^{-2}$.

The sugar analysis of the optimised extracts (Table 3 ) shows that they were composed of $47 \%$ polysaccharides rich in xylose and arabinose residues. These extracts also contained residual amounts of uronic acids and galactose. In contrast to the previous extracts no glucose was detected. Methylation analysis (Table 4) confirmed the presence of AX due to the highest molar percentage of 4-Xylp and the t-Araf, together with all other sugar residues characteristic of AX, namely 2,4-Xylp, 3,4-Xylp and 2,3,4-Xylp considered as the common substitution linkages to the arabinofuranose residues. The presence of 5-Araf indicates that the extracted AX were feruloylated [1]. The presence of 4-Glcp could be considered as a residual when compared to the previous US and AC extracts. The presence of 3-Galp, 6-Galp and 3,6-Galp simultaneously with 2-Araf and 3,5-Araf suggests the presence of a residual type II arabinogalactans (AG). Residual AG have also been reported in literature in barley and barley malt [28].

\subsection{Optimisation of AKE of arabinoxylan-rich extracts from BSG by RSM}

The conventional alkaline extraction (AKE) was also optimised by RSM for the optimum yield of polymeric material, obtained by ethanol precipitation followed by dialysis. The experimental design and corresponding response values are presented in Table 5. The independent variables optimised were (i) weight of sample to the volume of solvent ( $\mathrm{w} / \mathrm{v}$ ratio, in the range of $0.08-0.16$ ), (ii) alkali solution concentration (2-4 M), (iii) temperature (35$55^{\circ} \mathrm{C}$ ) and (iv) extraction time (4-10 h).

A regression analysis was carried out to fit the mathematical models to the experimental data and the regression coefficients 
(a)

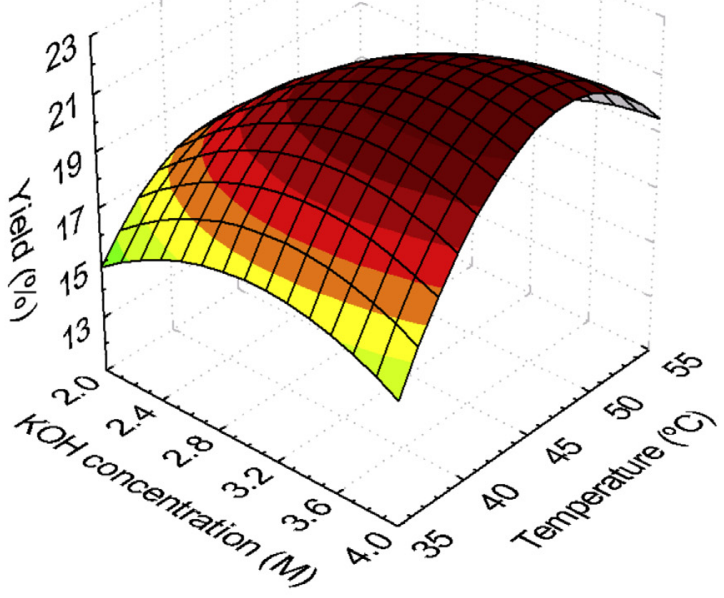

(b)

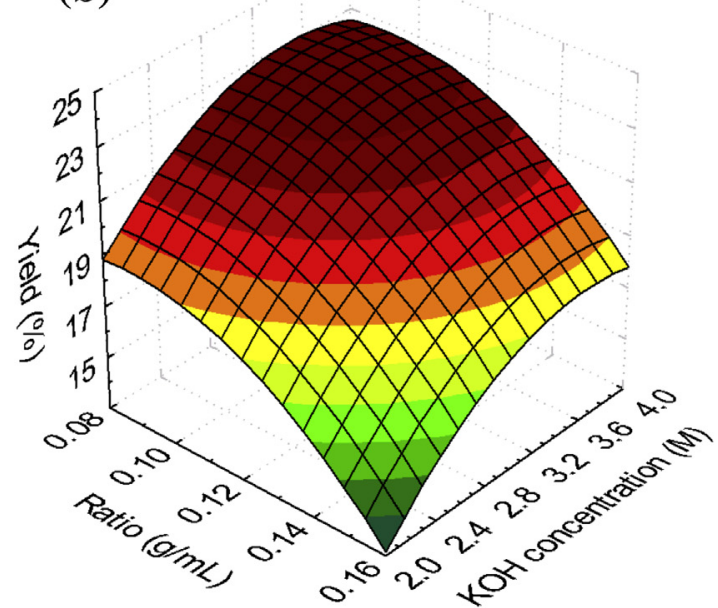

(c)

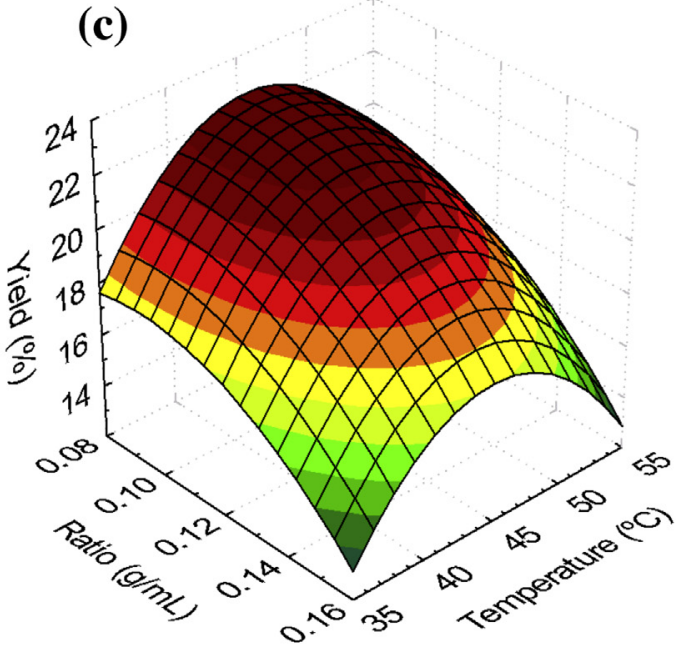

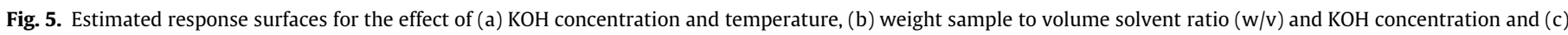
$\mathrm{w} / \mathrm{v}$ ratio and temperature on the yield of ethanol insoluble material (AE) obtained.

for the uncoded variables are shown in Table 6 . The model fitted explain $74.5 \%$ of the yield variability and the $p$-values of regression and ANOVA analysis showed three effects significantly influencing the yield, at $95 \%$ confidence level. The quadratic factor of extraction temperature $(\beta 33)$ is the main influence on yield $(p \leqslant 0.05)$, followed by the $\mathrm{w} / \mathrm{v}$ ratio $(\beta 1)$ and concentration of the alkali solution $(\beta 2)$.

The estimate response surfaces based on the experimental data (Fig. 5) shows that increasing temperature and alkali solution concentration promoted a yield increase. However, at higher temperatures there was a significant decrease in the yield (Fig. 5a and c). The influence of temperature on the xylans extraction was also reported by Hromádkova et al. [14], who suggested that the increase in the temperature and alkali concentration increased the degradation of xylans, and subsequently promoted the depolymerisation into shorter xylans that were soluble in ethanol solution. The increase in the $\mathrm{w} / \mathrm{v}$ ratio shows a decrease in the yield (Fig. 5b and c). Increasing the concentration of the alkali solution at the highest ratio did not show an influence on the final yield obtained (Fig. 5b), since increasing the sample weight for the same solvent volume seems to decrease the hydration and swelling processes.
The optimum yield, predicted by the regression Eq. (3) fitted to the data, was $23.2 \%$ by the combination of the factors, which maximised the yield over the studied region. This combination was $0.09(\mathrm{w} / \mathrm{v}), 3.7 \mathrm{M} \mathrm{KOH}, 47^{\circ} \mathrm{C}$ and $7.2 \mathrm{~h}$.

Since in UAE the ratio was limited to 0.04 , the alkaline extraction was performed using this ratio for the purposes of comparing the two methods. To maximise the yield using this ratio, the combination of the other factors were $3 \mathrm{M} \mathrm{KOH}, 45^{\circ} \mathrm{C}$ and $7 \mathrm{~h}$ and the predicted yield by the regression equation was $20.1 \%$ while the experimental value obtained was $20.3 \pm 1.7 \%(n=3)$.

The extracts obtained under the optimised conditions were composed of $76 \%$ polysaccharides and the major sugar residues identified were xylose followed by arabinose and residual amounts of uronic acids, glucose and galactose (Table 3). These extracts were richer in sugars than the USAE (47.4\%), although the major sugars and their glycosidic-linkage composition were similar. The highest molar percentages of 4-Xylp and t-Araf were indicating the major composition of $\mathrm{AX}$ (Table 4). The lower relative percentages of 2,4-Xylp, 3,4-Xylp and 2,3,4-Xylp in AE as compared to USAE showed the presence of less branched structures. The 4-Glcp linkage, indicative of the presence of residual starch, accounted for 8.5\% in AE whereas it was almost absent in USAE (0.8\%), indicating 
Table 7

Content of polysaccharides (AX, AG, $\beta$-glucans and starch) and protein of AX-rich extracts obtained from BSG

\begin{tabular}{|c|c|c|c|c|c|c|c|c|}
\hline & \multirow{2}{*}{$\begin{array}{l}\text { Yield } \\
(\%)\end{array}$} & \multicolumn{4}{|c|}{ Polysaccharides (\%) } & \multicolumn{2}{|l|}{$\mathrm{AX}$} & \multirow{2}{*}{$\begin{array}{l}\text { Protein } \\
(\%)\end{array}$} \\
\hline & & $\mathrm{AX}$ & AG & $\begin{array}{l}\beta- \\
\text { glucans }\end{array}$ & Starch & $\frac{\mathrm{Xyl} \mathrm{l}_{\text {total }}}{\mathrm{t}-\mathrm{Xyy}}$ & $\frac{\mathrm{Xyl}_{\mathrm{ram}}}{\mathrm{Xyl}_{\text {total }}}$ & \\
\hline US & 2 & 31 & 2 & 0.6 & 8 & 24 & 0.4 & 4 \\
\hline$A C$ & 1 & 21 & 1 & 0.1 & 16 & 22 & 0.4 & 8 \\
\hline USAE & 20 & 45 & 2 & - & 0.4 & 12 & 0.5 & 25 \\
\hline $\mathrm{AE}$ & 20 & 66 & 2 & 0.5 & 7 & 14 & 0.3 & 17 \\
\hline
\end{tabular}

US - ultrasound extract; AC - autoclave extract; USAE - ultrasound alkaline extract; AE - alkaline extract; AX - Arabinoxylans $\left(X_{\text {Xyl }}\right.$ total + Ara $_{\text {total }}-\left(\mathrm{Gal}_{\text {total }} \times 0.7 \times 180 /\right.$ $150)) ;$ AG - Arabinogalactans $\left(\mathrm{Gal}_{\text {total }}+\left(\mathrm{Gal}_{\text {total }} \times 0.7 \times 180 / 150\right)\right) ; \mathrm{Xyl}_{\mathrm{ram}}-(2,4-$ $\mathrm{Xyl}+3,4-\mathrm{Xyl}+2 \times 2,3,4-\mathrm{Xyl})$.

that the USAE is able to recover an extract almost devoid of starch. This could be attributed by the US and AC pre-treatments. In addition, a 3-Glcp linkage was also identified, also present in both US and $\mathrm{AC}$ extracts, suggesting the presence of residual $\beta$-glucans. The residual galactose linkages were also identified in these extracts but in low amounts, reflecting the presence of residual AG. The 2-Manp, 6-Manp and 2,6-Manp, which are typical linkages of mannoproteins found in the yeast used for production of the beer [30,31], were also present in residual amounts in the extract obtained under the optimised AKE conditions. The presence of mannoproteins may reflect some contamination of Saccharomyces in the BSG analysed.

\subsection{Ultrasound assisted extraction (UAE) vs alkaline extraction (AKE)}

A similar yield of polymeric material (20\%) was obtained in UAE when compared to the AKE reference method used. The final residue (FR) after the application of UAE was composed of fewer sugars than the FR after AKE but the quantity of AX remaining (30\%) was similar (Table 3). This means that the UAE was more efficient in extracting polysaccharides from the BSG than the AKE, and as efficient as AKE in extracting AX. However, the final extract USAE was composed of less sugars than the $\mathrm{AE}$ and the composition in AX was $45 \%$, while AE was composed of $66 \%$ AX (Table 7 ). The lower amount of AX and the results obtained in Section 3.1.2 suggests that UAE, although more efficient in the extraction of the polysaccharides from the cell walls of BSG, promotes their degradation and generates shorter polymers which are probably soluble in ethanol and/or lost in the dialysis step used in this work. The ratios of $\mathrm{Xyl}_{\text {total }} / \mathrm{t}-\mathrm{Xyl}$ and $\mathrm{Xyl}_{\mathrm{ram}} / \mathrm{Xyl}_{\text {total, }}$ determined for the USAE indicates that the $\mathrm{AX}$ in this extract were slightly smaller and more branched than those recovered in the $\mathrm{AE}$ (Table 7). Optimisation reflecting $A X$ yields using UAE should be done in order to improve the amount of $A X$ in the extracts obtained.

The composition of USAE and AE also differs with respect to the quantity of protein present and in the type and quantity of other polysaccharides (Table 7). In addition to the AX, USAE was also composed of $2 \% \mathrm{AG}$ and residual starch, while $\mathrm{AE}$ in addition to AX also contained $2 \%$ AG, $7 \%$ starch and residual amounts of $\beta$-glucans. The difference in the quantity of starch in the USAE, values these extracts when compared to the AE.

The extracts obtained with the pre-washing treatment revealed a considerable amount of $\mathrm{AX}, 31 \%$ in US extracts and $21 \%$ in $\mathrm{AC}$ extracts (Table 7). AX extracted with water showed a higher $\mathrm{Xyl}_{\text {total }} / \mathrm{t}$-Xyl, which is in accordance with Dervilly et al. [28] for barley and Mandalari et al. [6] for BSG. This type of AX has been correlated with higher prebiotic activity, however the high quantity of starch in these extracts and the high costs associated with its removal could hinder the application of these extracts as prebiotics.
As an example, using 1 tonne of BSG would result in $90 \mathrm{~kg}$ of AX being obtained using UAE, compared to $132 \mathrm{~kg}$ of AX using conventional alkaline method. However, the extracts obtained by UAE were almost absent of starch, which is a considerable economic advantage. The extract obtained with the conventional alkaline extraction from 1 tonne of BSG will have $14 \mathrm{~kg}$ of associated starch while the extract obtained with UAE will have only $0.8 \mathrm{~kg}$ of starch. The costs associated with starch removal will be much higher in the conventional method. These costs will also be compounded by energy costs of $7 \mathrm{~h}$ extraction at $45^{\circ} \mathrm{C}$, and the amount of alkaline reagent required in contrast with the $25 \mathrm{~min}$ UAE at room temperature and with less alkaline reagent used. Moreover, the amount of $\mathrm{AX}$ in the extracts produced by UAE can be improved if the optimisation reflecting $\mathrm{AX}$ yields will be considered.

The recovery of AX using the extracts obtained with the prewashing treatment seems to be much too expensive due to the presence of starch. However, the pre-washing treatment should not be skipped because it helps washing the residue for the following ultrasound alkaline treatment, leading to the production of extracts depleted of starch, which could enhance their potential prebiotic applications.

\section{Conclusion}

The efficiency of UAE in the production of AX-rich extracts from BSG was shown by the significant reduction in the extraction time and energy consumption, for possible industrial applications. Another advantage of the application of UAE is the removal of starch from the final AX-rich extract. The AX recovered by UAE were more branched than those recovered by AKE, which allows to set other extraction procedures in order to obtain AX structures for different possible applications.

\section{Acknowledgements}

The authors wish to acknowledge the Irish Department of Agriculture, Food and the Marine for their funding of this project (No. 08RDTAFRC665) under the Food Institutional Research Measure (FIRM) and FCT, the European Union, QREN, FEDER, COMPETE, for funding the Research Unit 62/94-QOPNA (project PEst-C/QUI/ UI0062/2013; FCOMP-01-0124-FEDER-037296) and the postdoctoral grant SFRH/BPD/70589/2010 of Elisabete Coelho. The authors are also grateful to Marcelo Melo from CICECO (University of Aveiro) that kindly offered his help and software to design the response surface plots.

\section{References}

[1] C. Grootaert, J.A. Delcour, C.M. Courtin, W.F. Broekaert, W. Verstraete, T. Van de Wiele, Microbial metabolism and prebiotic potency of arabinoxylan oligosaccharides in the human intestine, Trends Food Sci. Technol. 18 (2007) 64-71.

[2] R.G. Crittenden, M.J. Playne, Production, properties and applications of foodgrade oligosaccharides, Trends Food Sci. Technol. 7 (1996) 353-361.

[3] A.G.J. Voragen, Technological aspects of functional food-related carbohydrates, Trends Food Sci. Technol. 9 (1998) 328-335.

[4] M. Santos, J.J. Jiménez, B. Bartolomé, C. Gómez-Cordovés, M.J. del Nozal, Variability of brewer's spent grain within a brewery, Food Chem. 80 (2003) 1721.

[5] S.I. Mussatto, G. Dragone, I.C. Roberto, Brewers' spent grain: generation, characteristics and potential applications, J. Cereal Sci. 43 (2006) 1-14.

[6] G. Mandalari, C.B. Faulds, A.I. Sancho, A. Saija, G. Bisignano, R. LoCurto, K.W. Waldron, Fractionation and characterisation of arabinoxylans from brewers' spent grain and wheat bran, J. Cereal Sci. 42 (2005) 205-212.

[7] E. Vieira, M.A.M. Rocha, E. Coelho, O. Pinho, J.A. Saraiva, I.M.P.L.V.O. Ferreira, M.A. Coimbra, Valuation of brewer's spent grain using a fully recyclable integrated process for extraction of proteins and arabinoxylans, Ind. Crops Prod. 52 (2014) 136-143.

[8] C.B. Faulds, G. Mandalari, R.B. Lo Curto, G. Bisignano, K.W. Waldron, Influence of the arabinoxylan composition on the susceptibility of mono- and dimeric 
ferulic acid release by Humicola insolens feruloyl esterases, J. Sci. Food Agric. 86 (2006) 1623-1630.

[9] F. Carvalheiro, M.P. Esteves, J.C. Parajó, H. Pereira, F.M. Girio, Production of oligosaccharides by autohydrolysis of brewery's spent grain, Bioresour. Technol. 91 (2004) 93-100.

[10] E. Coelho, M.A.M. Rocha, J.A. Saraiva, M.A. Coimbra, Microwave superheated water and dilute alkali extraction of brewers' spent grain arabinoxylans and arabinoxylo-oligosaccharides, Carbohydr. Polym. 99 (2014) 415-422.

[11] A. Ebringerová, Z. Hromádková, An overview on the application of ultrasound in extraction, separation and purification of plant polysaccharides, Cent. Eur. J. Chem. 8 (2010) 243-257.

[12] R. Seshadri, J. Weiss, G.J. Hulbert, J. Mount Ultrasonic processing influences rheological and optical properties of high-methoxyl pectin dispersions, Food Hydrocolloid. 17 (2003) 191-197.

[13] A. Ebringerova, Z. Hromadkova, J. Alfodi, V. Hribalova, The immunologically active xylan from ultrasound-treated corn cobs: extractability, structure and properties, Carbohydr. Polym. 37 (1998) 231-239.

[14] Z. Hromádková, J. Kováčiková, A. Ebringerová, Study of the classical and ultrasound-assisted extraction of the corn cob xylan, Ind. Crops Prod. 9 (1999) 101-109.

[15] A. Ebringerová, Z. Hromádková, Effect of ultrasound on the extractibility of corn bran hemicelluloses, Ultrason. Sonochem. 9 (2002) 225-229.

[16] R.C. Sun, X.F. Sun, X.H. Ma, Effect of ultrasound on the structural and physiochemical properties of organosolv soluble hemicelluloses from wheat straw, Ultrason. Sonochem. 9 (2002) 95-101.

[17] R.C. Sun.J. Tomkinson, Characterization of hemicelluloses obtained by classical and ultrasonically assisted extractions from wheat straw, Carbohydr. Polym. 50 (2002) 263-271.

[18] Z. Hromádková, A. Ebringerová, Ultrasonic extraction of plant materialsinvestigation of hemicellulose release from buckwheat hulls, Ultrason. Sonochem. 10 (2003) 127-133.

[19] J.X. Sun, R.C. Sun, X.F. Sun, Y.Q. Su, Fractional and physico-chemical characterization of hemicelluloses from ultrasonic irradiated sugarcane bagasse, Carbohydr. Res. 339 (2004) 291-300.
[20] Z. Hromádková, Z. Košt’álová, A. Ebringerová, Comparison of conventional and ultrasound-assisted extraction of phenolics-rich heteroxylans from wheat bran, Ultrason. Sonochem. 15 (2008) 1062-1068.

[21] A. Ebringerová, Z. Hromádková, Z. Koštálová, V. Sasinková, Chemical valorization of agricultural by-products: Isolation and characterization of xylan-based antioxidants from almond shell biomass, BioRes. 3 (2008) 60-70.

[22] J.P. Lorimer, T.J. Mason, T.C. Cuthbert, E.A. Brookfield, Effect of ultrasound on the degradation of aqueous native dextran, Ultrason. Sonochem. 2 (1995) S55S57.

[23] M.A. Coimbra, I. Delgadillo, K.W. Waldron, R.R. Selvendran, Isolation and analysis of cell wall polymers from olive pulp, in: H.F. Linskens, J.F. Jackson (Eds.), Modern Methods of Plant Analysis, Springer, Berlin, 1996, pp. 19-44.

[24] R.R. Selvendran, J.F. March, S.G. Ring, Determination of aldoses and uronic acid content of vegetable fiber, Anal. Biochem. 96 (1979) 282-292.

[25] I. Ciucanu, F. Kerek, A simple and rapid method for the permethylation of carbohydrates, Carbohydr. Res. 131 (1984) 209-217.

[26] P.J. Harris, R.J. Henry, A.B. Blakeney, B.A. Stone, An improved procedure for the methylation analysis of oligosaccharides and polysaccharides, Carbohydr. Res. 127 (1984) 59-73.

[27] E. Coelho, S.M. Rocha, M.A. Coimbra, Foamability and foam stability of molecular reconstituted model sparkling wines, J. Agric. Food Chem. 59 (2011) $8770-8778$

[28] G. Dervilly, C. Leclercq, D. Zimmermann, C. Roue, J.F. Thibault, L. Saulnier Isolation and characterization of high molar mass water-soluble arabinoxylans from barley and barley malt, Carbohydr. Polym. 47 (2002) 143-149.

[29] C.B. Faulds, S. Collins, J.A. Robertson, J. Treimo, V.G.H. Eijsink, S.W.A. Hinz, H.A. Schols, J. Buchert, K.W. Waldron, Protease-induced solubilisation of carbohydrates from brewers' spent grain, J. Cereal Sci. 50 (2009) 332-336.

[30] G. Lesage, H. Bussey, Cell wall assembly in Saccharomyces cerevisiae, Microbiol. Mol. Biol. R. 70 (2006) 317-343.

[31] P.N. Lipke, R. Ovalle, Cell wall architecture in yeast: new structure and new challenges, J. Bacteriol. 180 (1998) 3735-3740. 